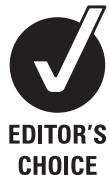

- Additional materials are published online only. To view these files please visit the journal online (http://jnnp.bmj. com)

Menzies Research Institute Tasmania, University of Tasmania, Hobart, Australia

\section{Correspondence to} Associate Professor Bruce Taylor, Menzies Research Institute Tasmania, University of Tasmania, Private Bag 23, Hobart TAS 7001, Australia; bruce.taylor@utas.edu.au

Received 6 January 2011 Revised 21 February 2011 Accepted 23 February 2011 Published Online First 8 April 2011

\title{
Latitude is significantly associated with the prevalence of multiple sclerosis: a meta-analysis
}

\author{
Steve Simpson Jr, Leigh Blizzard, Petr Otahal, Ingrid Van der Mei, Bruce Taylor
}

\begin{abstract}
Background There is a striking latitudinal gradient in multiple sclerosis (MS) prevalence, but exceptions in Mediterranean Europe and northern Scandinavia, and some systematic reviews, have suggested that the gradient may be an artefact. The authors sought to evaluate the association between MS prevalence and latitude by meta-regression.
\end{abstract}

Methods and findings Studies were sourced from online databases, reference mining and author referral. Prevalence estimates were age-standardised to the 2009 European population. Analyses were carried out by means of random-effects meta-regression, weighted with the inverse of within-study variance. The authors included 650 prevalence estimates from 321 peerreviewed studies; 239 were age-standardised, and 159 provided sex-specific data. The authors found a significant positive association (change in prevalence per degree-latitude) between age-standardised prevalence $(1.04, p<0.001)$ and latitude that diminished at high latitudes. Adjustment for prevalence year strengthened the association with latitude (2.60, $\mathrm{p}<0.001)$. An inverse gradient in the Italian region reversed on adjustment for MS-associated HLA-DRB1 allele distributions. Adjustment for HLA-DRB1 allele frequencies did not appreciably alter the gradient in Europe. Adjustment for some potential sources of bias did not affect the observed associations.

Conclusion This, the most comprehensive review of MS prevalence to date, has confirmed a statistically significant positive association between MS prevalence and latitude globally. Exceptions to the gradient in the Italian region and northern Scandinavia are likely a result of genetic and behavioural-cultural variations. The persistence of a positive gradient in Europe after adjustment for HLA-DRB1 allele frequencies strongly supports a role for environmental factors which vary with latitude, the most prominent candidates being ultraviolet radiation (UVR)/ vitamin D.

\section{INTRODUCTION}

It has long been recognised that there is a distinct latitudinal variation in multiple sclerosis (MS) frequency, higher latitude correlating with increased prevalence, incidence and mortalities. Understanding the geoepidemiology of MS can be a valuable source of environmental and genetic aetiological clues. MS geoepidemiology has thus become a major research focus, and the latitudinal gradient hypothesis a point of contention. ${ }^{1-6}$ While gradients have been demonstrated in Australasia, ${ }^{7} 8$ Japan, $^{9}$ Europe $^{10}$ and North America, ${ }^{11}$ other studies ${ }^{12}{ }^{13}$ have found no association between prevalence and latitude. Also, studies in Mediterranean Europe have found higher-thanexpected prevalence for their latitudes, while studies in northern Scandinavia ${ }^{14}$ have found a lower-than-expected prevalence. This has led some ${ }^{346}$ to suggest that the gradient is an artefact.

While individual studies have provided evidence, the only way to evaluate the geoepidemiology of $\mathrm{MS}$ is to combine findings from a number of studies, and there have been few of these. Early work by Kurtzke ${ }^{1}$ described bands of high, medium and low frequency, later revised to vary with longitude. ${ }^{2}$ However, in a 1994 review of MS epidemiology in Europe ${ }^{15}$ and a 2001 review globally, ${ }^{3}$ Rosati argued that the linear gradient hypothesis was an oversimplification, pointing particularly to studies undertaken in Mediterranean Europe after 1980 which found a high prevalence in a Kurtzke medium-prevalence zone, ${ }^{12}$ and instead proposed that much of the variation in frequency was due to different genetic susceptibilities.

The first meta-analysis of MS geoepidemiology was done by Zivadinov and colleagues in $2003,{ }^{4}$ combining data from 69 prevalence and 22 incidence estimates between 1980 and 1998. Importantly, in addition to analysing crude values, Zivadinov age-standardised prevalence, reporting a significant gradient in the crude analysis that was attenuated on age standardisation. The authors reported that no association between latitude and incidence was found after age standardisation, however.

In 2008, Alonso and Hérnan undertook a metaanalysis of MS incidence, including 38 age-standardised incidence estimates between 1966 and $2007 .{ }^{5}$ These authors found that, in contradiction with the findings by Zivadinov, ${ }^{4}$ there was a significant association between incidence and latitude, though moderated after 1980.

Recently, Koch-Henriksen and Sørensen ${ }^{6}$ published findings from a meta-analysis of 97 crude MS prevalence and 122 incidence estimates, reporting 'modest' associations between prevalence and latitude in Western Europe and North America. The authors found no association between incidence and latitude within Western Europe or North America. Surprisingly, in Australasia, an archetype of the latitudinal gradient, ${ }^{7} 8$ the authors reported that there was no association between latitude and prevalence, or incidence after adjusting for study prevalence year.

The systematic reviews of MS prevalence geoepidemiology, ${ }^{4}{ }^{6}$ particularly that by KochHenriksen and Sørensen, ${ }^{6}$ had some significant methodological shortcomings that may have influenced their results. Further, in light of our own findings regarding the relationship between latitude 
and UV/vitamin D and MS risk ${ }^{16}$ and clinical course, ${ }^{17} 18$ we sought to re-evaluate the geoepidemiology of MS prevalence using a meta-analysis study design.

\section{METHODS}

\section{Literature search}

We searched PubMed (http://www.pubmed.org), EMBASE (http://www.embase.com) and ISI Web of Knowledge (http:// www.isiknowledge.com) for articles matching the keywords 'multiple sclerosis AND prevalence' or 'multiple sclerosis AND epidemiology' for all publications which could be found up to publication year 2010. In addition, article bibliographies were screened, and some authors referred us to other prevalence studies.

\section{Inclusion criteria}

To be included, studies needed to have provided crude and/or age-specific prevalence estimates with definition of the study area, source population and study period. Where this information was not reported, this information was sought from the study authors. The majority of scientific articles were published in English, but also included were articles written in Latin and Cyrillic-based alphabets. Articles were translated by the first author or using online translation software (http://translate. google.com).

\section{Data collection}

The following information was abstracted from the study reports: study area, the study prevalence year or final year of a period-prevalence study, the diagnostic criteria used, the source and study populations, and the crude and/or age-specific prevalence data.

\section{HLA analysis}

HLA-DRB1 allele frequencies for Europe were obtained from the online database http://www.allelefrequencies.net ${ }^{19}$ or individual publications.

\section{Statistical analysis Crude prevalence}

Crude prevalence was calculated as the number of prevalent cases ascertained in each study divided by the number of persons in the study population. Where the population size was not reported and was not available from local statistical sources, it was approximated from the reported prevalence estimates and the reported number of cases. The variance of each prevalence estimate was calculated using standard methods. ${ }^{20}$

\section{Age standardisation}

Where age-specific data were available, age-standardised prevalence was calculated by the direct method ${ }^{20}$ using each of three standard populations: 2009 World, 2009 Australia and 2009 Europe. $^{21}$ We found no meaningful differences using the different standard populations, and only those for the 2009 Europe population are reported. The variance of each agestandardised prevalence estimate was calculated using standard methods. $^{20}$

\section{Transformation and study weighting}

The prevalence estimates were transformed if necessary to reduce heteroskedasticity for regression analyses. ${ }^{22}$ For example, age-standardised prevalence estimates were analysed on a logarithmic scale. Each prevalence estimate was weighted by the inverse of its variance, with the variance of transformed estimates approximated using the Delta method.

\section{Meta-regression \\ Heterogeneity}

There was considerable between-study variance in the prevalence estimates, as evidenced by the restricted maximum likelihood estimate of between-study variance, $\tau^{2}$, Cochran's $\mathrm{Q}$-statistic and the $\mathrm{I}^{2}$ statistic. The results for global prevalence $\left(\tau^{2}=1.237, \mathrm{Q}=3.1 \times 10^{8}, \mathrm{p}<0.0001, \mathrm{I}^{2}=100 \%\right)$, global prevalence with age-specific data $\left(\tau^{2}=0.783, Q=6.3 \times 10^{7}, \quad p<0.0001\right.$, $\left.\mathrm{I}^{2}=100 \%\right)$ and age-standardised global prevalence $\left(\tau^{2}=0.764\right.$, $\left.Q=4.1 \times 10^{5}, p<0.0001, I^{2}=99.43 \%\right)$ were each inconsistent with a shared common effect size.

Because it was not reasonable to assume that all the heterogeneity could be explained by model covariates, random-effects meta-regression models were fitted using STATA/SE for Windows (Version 10.1).

\section{Adjustment for covariates}

Covariates were specified a priori, in keeping with our hypothesis that prevalence varies with latitude. Other covariates included prevalence year, the diagnostic criteria used and the inclusion of possible cases.

All regression models included adjustment for prevalence year because, on average, the prevalence estimates increased with time. Most models included a binary covariate for the type of diagnostic criteria used ( $1=$ Poser criteria and its variants, 2001 McDonald criteria or $2005 \mathrm{McDonald} /$ Polman criteria, $0=$ all other diagnostic criteria or studies not specifying or not using systematic diagnostic criteria). In addition, some models included a binary covariate for inclusion of cases classified as possible MS ( $1=$ possible cases included, $0=$ possible cases not included). To improve the fit to the data, some models included a product term formed from the covariates for prevalence year and diagnostic criteria, and a second product-term formed from the covariates for diagnostic criteria and possible cases. The estimates reported are those for the year 2009 and are calculated at the mean levels of the other covariates.

\section{Time-corrected analysis}

The prevalence estimates depicted in figure 1 for each study (the centres of the circles) are the predicted values from a regression model containing covariates for latitude and actual prevalence year but calculated with prevalence year set at 2009. They are estimates of the values that would have been obtained had each study been conducted in 2009 .

\section{Segmented analysis}

Examination of the data revealed that the positive association between prevalence and latitude became less pronounced at high latitudes. To accommodate this, segmented models were fitted for supra-regions (global, Western Europe and Europe overall) that non-exclusively included areas located at high latitudes. The segmented models included a covariate for latitude when fitted for latitudes less than or equal to a threshold latitude $\left(\mathrm{L}_{0}\right)$, and covariates for latitude and its square when fitted for latitudes greater than the threshold. This paper reports the results of a test of the coefficient of the quadratic term. To estimate the threshold value, the segmented model was first estimated by weighted non-linear least-squares minimisation using the PROC NLIN procedure in SAS (Version 9.2). The estimated thresholds for the global model were $\mathrm{L}_{0}=54.4^{\circ}$ (crude prevalence), $\mathrm{L}_{0}=50.7^{\circ}$ (crude 
prevalence with age-specific data available) and $\mathrm{L}_{0}=48.8^{\circ}$ (age-standardised prevalence).

\section{Adjustment for HLA-DRB1}

To assess the contribution of differences in population frequencies of several key MS-associated HLA-DRB1 alleles (HLADRB1*15, ${ }^{*} 11, * 01,{ }^{*} 03$ and $\left.{ }^{*} 14\right)$ to the latitudinal gradient within Europe, linear covariates were added for each allele.

\section{Latitudinal gradient by sex}

Sex-specific gradients in age-standardised prevalence with latitude were estimated in a model that included a binary covariate for sex $(1=$ females, $0=$ males $)$ and a product-term formed from the covariates for latitude and sex. A statistical test of the coefficient of the product-term was used to compare the latitudinal gradients for males and females. Because the agestandardised prevalence estimates had been log-transformed for analysis, this was equivalent to a test of whether the female-tomale ratio of age-standardised prevalence varied by latitude. A test of whether the female-to-male ratio of age-standardised prevalence varied by prevalence year was conducted as a test of the coefficient of a product term formed from the covariates for prevalence year and sex.

\section{RESULTS}

\section{Review of literature}

Literature searches using the keywords 'multiple sclerosis AND prevalence' or 'multiple sclerosis AND epidemiology' produced 9379 and 14808 results respectively. Additional studies were found by searching article references and from author referrals. A total of 365 studies, of which 321 were peer-reviewed, satisfied our inclusion criteria. Only the peer-reviewed studies were used in analyses unless otherwise specified. This provided 650 prevalence estimates, of which 239 could be age-standardised, and 159 of these included sex-specific data. The distribution of all prevalence estimates is depicted in figure 2 .

Information about the studies is summarised in table 1. More detailed information including study area, latitude and prevalence year, diagnostic criteria, and prevalence estimates are shown in supplement 1. Diagnostic criteria used in each study are outlined in supplement 2. Rationales for allocation of study areas to study regions are described in supplement 3 . Data on HLA-DRB1 allele frequencies for each study area in Europe for which data could be obtained are shown in supplement 4.

\section{Global analyses}

Prevalence was significantly ( $p=0.001$ ) associated with latitude. Restricting the analysis to prevalence estimates that could be age-standardised attenuated the association, but it remained statistically significant $(p=0.001)$ including after age standardisation $(p<0.001)$. On average, the prevalence estimates increased with prevalence year $(p<0.001$, data not shown). Adjusted for prevalence year, the strength of the association between prevalence and latitude increased in all analyses. Further adjusting for diagnostic criteria and inclusion of possible cases slightly reduced the latitudinal gradient vis-à-vis adjustment for prevalence year alone (table 2).

\section{Models allowing a decreasing gradient at high latitudes}

A model that allowed additional covariates for latitude and its square to be fitted for high latitudes provided evidence of curvature that was statistically significant $(p<0.001)$ in each prevalence analysis (figure 1).
Table 3 shows the change in prevalence per degree latitude at five latitude degree increments for each of the analysis types. As in table 2, the gradient is most potent when all prevalences are included; the gradient is moderated on restriction to crude prevalence with age-specific data, and enhanced on age standardisation. Also, similar to the trend lines in figure 1, the gradient increases steadily with increasing latitude, reaching a peak around $55^{\circ}$, before changing to a significant inverse gradient above $60^{\circ}$.

\section{Regional analyses}

In regional analyses (table 4, figure 3), a statistically significant positive gradient was found within Australasia, the UK region, Atlantic and Central Europe, North America, and Western Europe overall. A statistically significant inverse gradient was found within the Scandinavia and North Atlantic, and Italian regions.

For nations of largely European descent (Europe, Australasia, North America, Latin America excluding the French West Antilles and Israel), the latitudinal gradient in age-standardised prevalence was 3.97 (95\% CI 2.27 to 5.66) cases/100 000 per degree of latitude. For all other nations for which we had prevalence data, here defined as non-European descent, the latitudinal gradient was -0.07 ( $95 \% \mathrm{CI}-1.07$ to 0.93 ) cases/ 100000 per degree of latitude, and the difference in trend was statistically significant $(\mathrm{p}=0.04)$.

\section{Adjustment for HLA-DRB1}

Table 5 shows the effects of adjustment for the frequencies of several HLA-DRB1 alleles on the gradients within Europe. The significant inverse gradient in the Italian region was completely reversed on adjustment, while the positive gradient for Western Europe was almost unchanged and that for Europe enhanced by $33.4 \%$.

\section{Latitudinal gradient by sex}

The global latitudinal gradients in age-standardised prevalence for males and females were 4.09 (95\% CI 2.80 to 5.39 ) and 7.19 (95\% CI 4.84 to 9.53 ) cases/100000 per degree of latitude respectively, at the mean global latitude. These estimates were not statistically distinguishable $(p=0.358)$, and hence there was no statistically significant change in the female/male ratio of age-standardised prevalence with latitude. At latitudes up to $59^{\circ}$, the prevalence sex ratio was 2.03 (95\% CI 1.71 to 2.42 ) but without any evidence of significant change with latitude over this range $(\mathrm{p}=0.768)$; above latitude $59^{\circ}$, the prevalence sex ratio was 1.59 (95\% CI 1.25, 2.02), but again without any evidence of a significant change with latitude over this range $(p=0.386)$.

The prevalence sex ratio did increase over time, increasing from 1.38 in 1949 to 2.34 in 2009, but this did not reach statistical significance $(p=0.12)$ in this sample size. Evaluating the change in prevalence sex ratio within regions revealed no significant change over latitude in any region; however, there was a statistically significant increase in the prevalence sex ratio over time in Australasia $(p=0.023)$ and the UK region $(p=0.003)$.

\section{Exclusion of serial measures}

Serial measurements within one location-most commonly in high-prevalence areas of Europe, North America and Australasia-effectively resample the same population if closely spaced in time. To evaluate potential bias, we restricted the analyses to the most recent prevalence estimates for each location and found that this made no material difference to the results (data not shown). 
Figure 1 Plot of time-corrected prevalence against latitude. (A) All crude prevalence estimates; (B) crude prevalence estimates restricted to those that could be age-standardised; (C) prevalence age-standardised to the 2009 Europe population. The area of each circle is proportional to the inverse of the variance of the prevalence estimates.
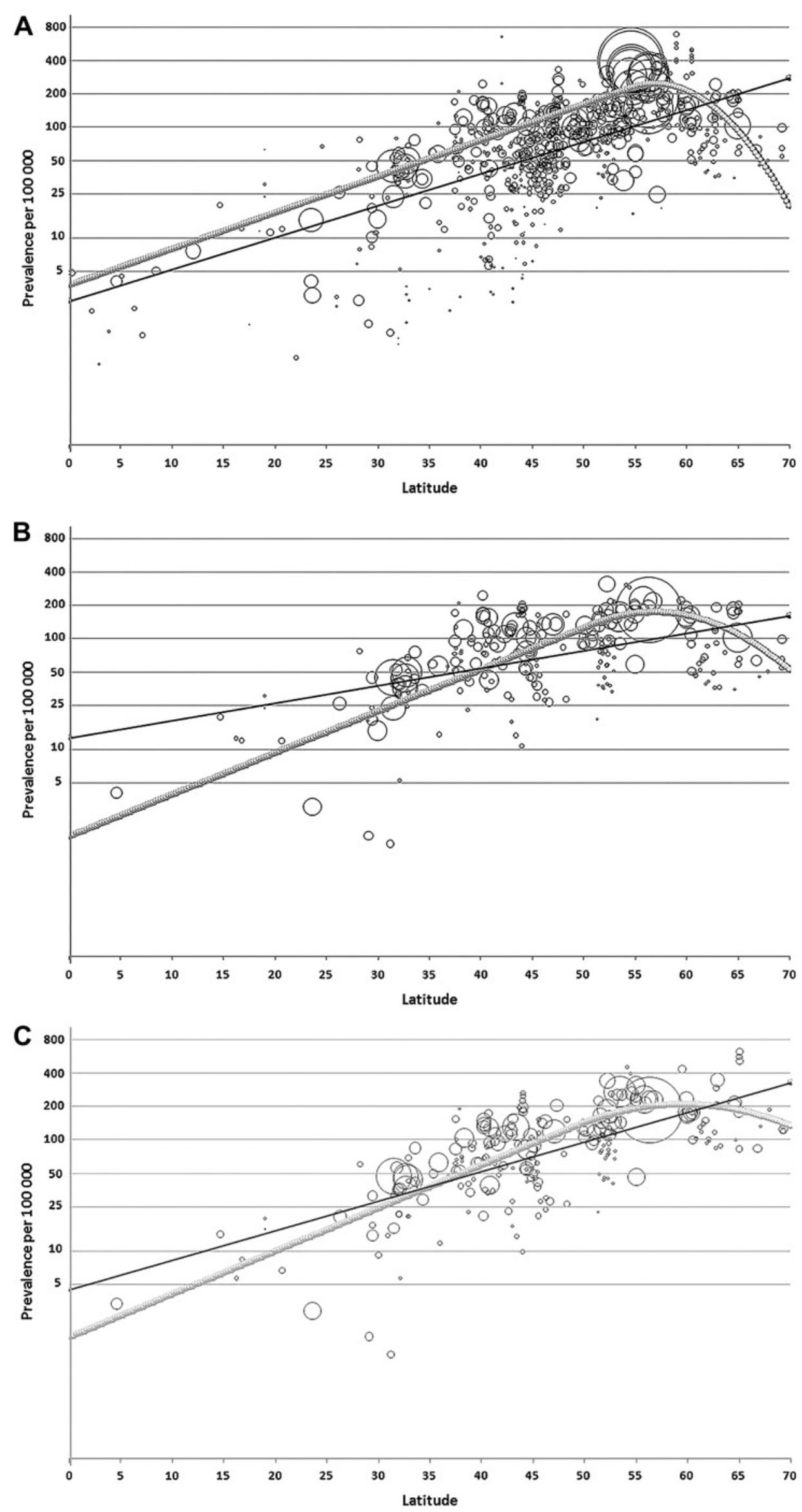


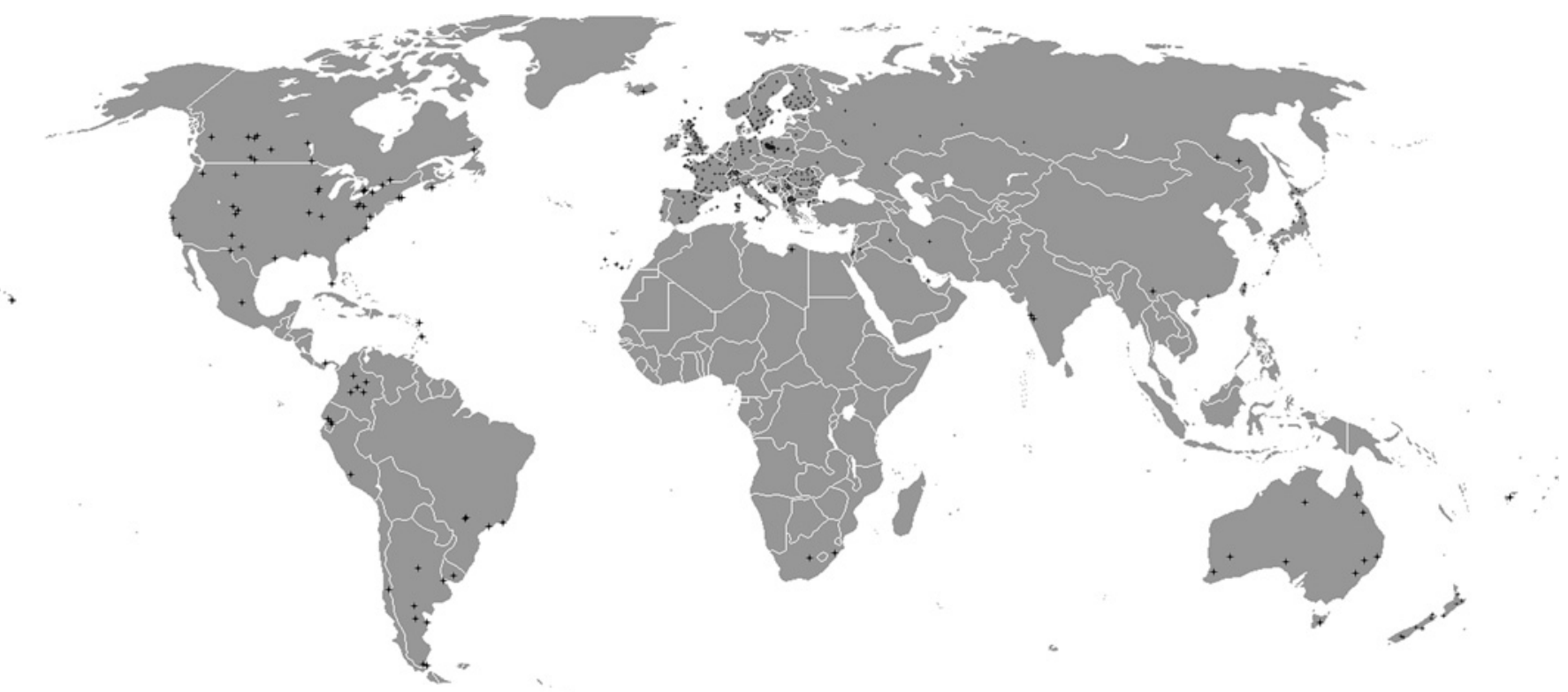

Figure 2 World map showing the distribution of all prevalence estimates included in this meta-analysis.

Exclusion of non-systematic diagnostic criteria

Another potential source of bias was the inclusion of studies using non-systematic MS diagnostic criteria. Excluding these studies resulted in no material changes in the estimated associations between prevalence and latitude (data not shown).

\section{Inclusion of non-peer-reviewed studies}

Excluded from all analyses thus far were studies $(n=47)$ that were not peer-reviewed. Including them made no material difference (data not shown).

\section{DISCUSSION}

This is the most comprehensive meta-analysis of MS prevalence studies yet undertaken, including 650 prevalence estimates from 321 peer-reviewed studies in 59 countries between 1923 and 2009. We found a strong and statistically significant latitudinal gradient for prevalence globally, which persisted on age standardisation and was enhanced on adjustment for prevalence year. The latitudinal gradient was observed only among nations of largely European descent, and while the distribution of HLA-DRB1 alleles did not explain the positive gradient in Europe or Western Europe, adjustment for HLA-DRB1 allele distribution reversed the inverse gradient in the Italian region. Similar gradients were observed for males and females, and the prevalence sex ratio did not change with latitude, or over time.

\section{Exceptions to the gradient}

European versus non-European populations

That there was a significant association between latitude and prevalence for European-descent regions, which was absent for regions of largely non-European-descent, suggests the presence of gene-environment interactions. This is not unexpected, given the higher frequencies of high-risk alleles for MS in

Table 1 Regional distribution of the 321 studies and their prevalence estimates

\begin{tabular}{|c|c|c|c|c|}
\hline & Studies & Prevalence estimates & $\begin{array}{l}\text { Age-standardised prevalence } \\
\text { estimates }\end{array}$ & $\begin{array}{l}\text { Sex-specif } \\
\text { prevalence }\end{array}$ \\
\hline Australasia & $16(16)$ & $31(31)$ & $27(27)$ & $26(26)$ \\
\hline \multicolumn{5}{|l|}{ Western Europe } \\
\hline UK and Ireland & $36(40)$ & $47(54)$ & $21(24)$ & $21(24)$ \\
\hline Scandinavia and North Atlantic & $41(41)$ & $101(102)$ & $41(41)$ & $18(18)$ \\
\hline Atlantic and Central Europe & $48(57)$ & $130(143)$ & $20(20)$ & $18(18)$ \\
\hline Italian region & $55(59)$ & $66(71)$ & $31(31)$ & $30(30)$ \\
\hline Eastern Europe & $39(51)$ & $144(184)$ & $48(49)$ & $16(17)$ \\
\hline North America & $43(47)$ & $58(62)$ & $30(30)$ & $13(13)$ \\
\hline Latin America and Caribbean & $2(17)$ & $21(28)$ & $4(4)$ & $4(4)$ \\
\hline Middle East and Africa* & $16(21)$ & $20(25)$ & $11(12)$ & $9(10)$ \\
\hline Asia and Pacific & $16(16)$ & $32(32)$ & $6(6)$ & $4(4)$ \\
\hline Total & $321(365)$ & 650 (732) & $239(244)$ & $159(164)$ \\
\hline
\end{tabular}

Numbers in parentheses include non-peer-reviewed studies. National designations are as follows: Australasia (including Australia and New Zealand); UK region (including the United Kingdom of Greater Britain and Northern Ireland (England, Northern Ireland, Scotland and Wales, the Republic of Ireland, and the Orkney Islands (UK); Scandinavia and North Atlantic (including Denmark, Finland, Iceland, Norway, Sweden, the Faroe Islands (Denmark), and the Shetland Islands (UK)), Atlantic and Central Europe (including Belgium, the Czech Republic, France, Germany, The Netherlands, Portugal, Spain (continental, the Balearic Islands and the Canary Islands) and Switzerland); Italian Region (including Peninsular and Insular Italy, San Marino and the island-region of Corsica of France); Eastern Europe (including Albania, Bosnia-Herzegovina, Bulgaria, Croatia, Estonia, Greece, Hungary, Lithuania, Macedonia, Poland, Romania, Russia, Serbia, Ukraine and the country formerly known as Yugoslavia); North America (including Canada, and continental and insular United States of America); Latin America and the Caribbean (including Argentina, Brazil,

Chile, Colombia, Ecuador, Mexico, Panama, Peru, Uruguay and the French West Antilles); the Middle East and Africa (including Iran, Iraq, Israel, Jordan, Kuwait, Libya, Malta Oatar, Saudi Arabia, South Africa and Turkey); Asia and Pacific Islands (including Fiji, India, Japan, the People's Republic of China and the Republic of China (Taiwan)).

*The nation of Malta is allocated to the Middle East and Africa region (see supplement 3 for rationale), but for analyses of Western Europe, Malta is included. 
Table 2 Estimated change in prevalence/100000 per degree of latitude showing the effect of adjustment for year of the study, use of systematic diagnostic criteria and inclusion of possible cases

\begin{tabular}{|c|c|c|c|}
\hline & \multirow[b]{2}{*}{$\begin{array}{l}\text { All crude } \\
\text { Slope }(95 \% \mathrm{CI})^{*}\end{array}$} & \multicolumn{2}{|c|}{ Prevalence estimates with age-specific data } \\
\hline & & $\begin{array}{l}\text { Crude } \\
\text { Slope }(95 \% \mathrm{CI})^{*}\end{array}$ & $\begin{array}{l}\text { Age-standardised } \\
\text { Slope }(95 \% \mathrm{CI})^{*}\end{array}$ \\
\hline Unadjusted & $1.58(1.30$ to 1.87$) \dagger$ & $0.81(0.34$ to 1.28$) \dagger$ & $1.04(0.51$ to 1.56$) \dagger$ \\
\hline $\begin{array}{l}\text { Adjusted for } \\
\text { prevalence year }\end{array}$ & $3.92(3.15$ to 4.70$) \dagger$ & $2.64(1.54$ to 3.74$) \dagger$ & $2.94(1.74$ to 4.15$) \dagger$ \\
\hline $\begin{array}{l}\text { Fully adjusted } \\
\text { model } \neq\end{array}$ & $3.32(2.57$ to 4.07$) \dagger$ & $2.30(1.27$ to 3.33$) \dagger$ & $2.60(1.44$ to 3.77$) \dagger$ \\
\hline
\end{tabular}

European populations. ${ }^{23}$ Interactions between the actual genes (eg, HLA-DRB1*1501) and environmental risk factors (eg, exposure to UV) are likely to exist, and the identification of those interactions is an emerging field of research. Moreover, other aspects such as epigenetic modifications and the timing of exposures further complicate the aetiology of MS.

\section{Italian region}

In the Italian region, we observed a significant inverse gradient. On adjustment for all HLA-DRB1 allele frequencies, the inverse gradient was reversed, yielding a positive gradient similar to the rest of Europe. This suggests that the inverse gradient in the region is entirely due to the unique distribution of HLA-DRB1 alleles in this area.

\section{Scandinavia and North Atlantic}

Because of a paucity of data on HLA-DRB1 allele frequencies by latitude in the Scandinavia region, we were unable to evaluate their role in this region. Populations in northern Scandinavia are a unique admixture of Swedes, Finns and Sámi. ${ }^{24}$ While none of the prevalence studies reported large proportions of low-risk groups such as the Sámi in their source populations $\left(11 \%^{14}{ }^{25}\right.$ to $12 \%^{26}$ ), it may be that ancestral components from the Sámi contribute to the lower prevalence at these latitudes.
A possible explanation for the inverse gradient in the region was suggested by Kampman and Brustad. ${ }^{27}$ While latitude correlates with reduced winter UVR and lower vitamin D, in Scandinavia higher latitude does not result in the low levels of serum vitamin $\mathrm{D}$ expected owing to high dietary intake. Particularly at the northern latitudes, ${ }^{27-30}$ dietary consumption of vitamin D in Scandinavia far exceeds that of other European populations, particularly in winter: dietary intake in peninsular Scandinavia ranges from 6.0 to $9.9 \mu \mathrm{g} /$ day, $^{29-31}$ while intake in continental Europe is lower, ranging from 2.0 to $3.3 \mu \mathrm{g} / \mathrm{day}^{32}$ Thus, despite the absence of vitamin $\mathrm{D}$-generating UV, mean serum vitamin $\mathrm{D}$ metabolite $(25(\mathrm{OH}) \mathrm{D})$ levels remain close to $50 \mathrm{nmol} / 1$ during winter at latitudes up to $71^{\circ} \mathrm{N} .^{29} 3133$ There is now substantial evidence that exposure to UV or vitamin D is associated with MS onset, ${ }^{34} 35$ and this increased dietary intake of vitamin D could contribute to the region's inverse gradient.

\section{HLA-DRB1 and the gradient in Europe}

Importantly, our analysis showed little effect on the latitudinal gradient in Europe after adjustment for the distribution of MSassociated HLA-DRB1 allele frequencies. This is in contradiction with others ${ }^{36}$ who found that the distribution of HLA-DRB1 accounted for $52 \%$ of the variation in prevalence by latitude in Europe, while the UV index accounted for only $31 \%$ in

Table 3 Estimated change in prevalence/100 000 per degree of latitude at increments of latitude

\begin{tabular}{|c|c|c|c|}
\hline \multirow[b]{2}{*}{ Latitude } & \multirow[b]{2}{*}{$\begin{array}{l}\text { All crude } \\
\text { Slope }(95 \% \mathrm{CI})^{*}\end{array}$} & \multicolumn{2}{|c|}{ Prevalence estimates with age-specific data } \\
\hline & & $\begin{array}{l}\text { Crude } \\
\text { Slope }(95 \% \mathrm{CI})^{*}\end{array}$ & $\begin{array}{l}\text { Age-standardised } \\
\text { Slope }(95 \% \mathrm{Cl})^{*}\end{array}$ \\
\hline 0 & $0.18(0.13$ to 0.22$) \dagger$ & & \\
\hline 5 & $0.25(0.20$ to 0.31$) \dagger$ & $0.47(0.33$ to 0.62$) \dagger$ & $0.51(0.36$ to 0.67$) \dagger$ \\
\hline 10 & $0.36(0.29$ to 0.43$) \dagger$ & $0.60(0.44$ to 0.77$) \dagger$ & $0.66(0.47$ to 0.84$) \dagger$ \\
\hline 15 & $0.51(0.43$ to 0.60$) \dagger$ & $0.77(0.57$ to 0.98$) \dagger$ & $0.84(0.62$ to 1.06$) \dagger$ \\
\hline 20 & $0.73(0.62$ to 0.85$) \dagger$ & $0.99(0.74$ to 1.24$) \dagger$ & $1.07(0.80$ to 1.35$) \dagger$ \\
\hline 25 & $1.04(0.89$ to 1.20$) \dagger$ & $1.27(0.95$ to 1.60$) \dagger$ & $1.37(1.01$ to 1.73$) \dagger$ \\
\hline 30 & $1.49(1.26$ to 1.71$) \dagger$ & $1.63(1.20$ to 2.07$) \dagger$ & $1.75(1.27$ to 2.23$) \dagger$ \\
\hline 35 & $2.12(1.78$ to 2.46$) \dagger$ & $2.09(1.48$ to 2.70$) \dagger$ & $2.24(1.57$ to 2.90$) \dagger$ \\
\hline 40 & $3.02(2.48$ to 3.56$) \dagger$ & $2.68(1.82$ to 3.54$) \dagger$ & $2.86(1.92$ to 3.80$) \dagger$ \\
\hline 45 & $4.31(3.44$ to 5.18$) \dagger$ & $3.43(2.21$ to 4.65$) \dagger$ & $3.66(2.33$ to 4.99$) \dagger$ \\
\hline 50 & $6.14(4.73$ to 7.55$) \dagger$ & $4.40(2.66$ to 6.14$) \dagger$ & $4.67(2.78$ to 6.56$) \dagger$ \\
\hline 55 & $9.61(7.08$ to 12.14$) \dagger$ & $6.13(3.45$ to 8.81$) \dagger$ & $6.51(3.60$ to 9.42$) \dagger$ \\
\hline 60 & $-3.17(-6.40$ to 0.05$)$ & $-0.94(-2.82$ to 0.94$)$ & $-1.15(-3.42$ to 1.13$)$ \\
\hline 65 & $-12.09(-15.75$ to -8.44$) \dagger$ & $-7.25(-10.90$ to -3.60$) \dagger$ & $-7.87(-12.07$ to -3.66$) \dagger$ \\
\hline 70 & $-9.25(-11.59$ to -6.92$) \dagger$ & $-8.34(-11.21$ to -5.47$) \dagger$ & $-8.90(-12.01$ to -5.80$) \dagger$ \\
\hline
\end{tabular}


Table 4 Region-specific associations between latitude and time-adjusted, age-standardised prevalence

\begin{tabular}{lcll}
\hline Region & $\begin{array}{c}\text { No of age-standardised } \\
\text { prevalence estimates }\end{array}$ & Midpoint latitude & Slope $\mathbf{9 5 \%} \mathbf{C l}^{*}$ \\
\hline Australasia & 27 & 35.51 & $8.38(5.77$ to 10.98$) \ddagger$ \\
Western Europe & 114 & 50.75 & $8.11(3.85$ to 12.35)† \\
$\quad$ UK region & 21 & 54.64 & $19.81(7.11$ to 32.51$) \dagger$ \\
Scandinavia and North Atlantic & 41 & 61.25 & $-4.29(-7.59$ to -0.99$) \dagger$ \\
$\quad$ Atlantic and Central Europe & 20 & 46.25 & $2.82(0.42$ to 5.21$) \dagger$ \\
$\quad$ Italian region & 31 & 41.32 & $-11.59(-20.17$ to -3.02$) \dagger$ \\
Eastern Europe & 48 & 47.24 & $-0.76(-4.67$ to 3.15$)$ \\
North America & 30 & 44.06 & $15.35(6.37$ to 24.32$) \ddagger$ \\
Latin America and the Caribbean & 4 & 20.76 & $0.06(-1.56$ to 1.68$)$ \\
Middle East and Africa & 11 & 31.83 & $1.62(4.26$ to 7.50$)$ \\
Asia and Pacific Islands & 6 & 32.94 & $0.90(-3.24$ to 5.03$)$ \\
\hline
\end{tabular}

${ }^{*}$ Slope $(95 \% \mathrm{Cl})=$ change in prevalence 100000 per degree of latitude $(95 \% \mathrm{Cl})$.

†Statistically significant $(\mathrm{p}<0.05)$.

$\ddagger$ Statistically significant $(p<0.001)$.

Data for Australasia, Western Europe including the UK region, the Scandinavia and North Atlantic region, the Atlantic and Central

Europe region, the Italian region, the Eastern Europe region, and Malta, North America, Latin America and the Caribbean, the Middle

East and Africa region, and the Asia and Pacific Islands region.

univariable analysis. In our analyses, we were able to assign HLA-DRB1 allele frequencies in Europe to a much finer degree than attempted previously, ${ }^{36}$ finding that adjustment for HLA-DRB1 frequencies increased the latitudinal gradient in Western Europe by $3.5 \%$ and the gradient in Europe overall by $33.4 \%$. These findings suggest a strong independent role for non-HLA-DRB1 factors in the gradient in Europe.

\section{Sex and prevalence sex ratio}

All trends observed in the total were mirrored in each sex, and no significant difference by sex was observed in any of our analyses. Globally, we found no significant change in the prevalence sex ratio (female/male) across the latitudinal range, nor within the intervals up to and above $59^{\circ}$. We found a $70 \%$ increase in the prevalence sex ratio over the 60-year interval for which we have prevalence data, but this did not reach statistical significance in this sample size. These results are different from those reported elsewhere, ${ }^{6}$ and may reflect the different methods and data included. On examining changes within regions, in no instance did we find a significant change in the prevalence sex ratio over latitude. In some regions, we found an increase in the prevalence sex ratio over time, including significant increases in
Australasia and the UK region, while in other regions such as North America, an increase was found but did not reach statistical significance. These regional findings are somewhat in conflict with the significantly increasing prevalence sex ratio over latitude in New Zealand ${ }^{8}$ and the significantly increasing prevalence sex ratio over time in Canada. ${ }^{37}$ This disparity may reflect less comprehensive coverage of these regions in our analysis, since a minority of studies provided age and sex-specific prevalence data.

\section{Strengths and improvements from previous studies}

This study makes significant improvements upon previous meta-analyses by Koch-Henriksen and Sørensen, ${ }^{6}$ and Zivadinov, ${ }^{4}$ and preceding descriptive reviews, ${ }^{1-3}$ in a number of key elements. These methodological improvements, in both data collection and statistical analysis, provide strong support in favour of our conclusions, and no doubt explain the differential findings from previous studies.

At the most basic, our study is more comprehensive, encompassing a broader range of studies, both geographical and temporal, that satisfy the inclusion criteria. This is due to our use of multiple data sources, as well as our inclusion of studies
Figure 3 Region-specific gradients per degree of latitude for Australasia, Western Europe and North America.

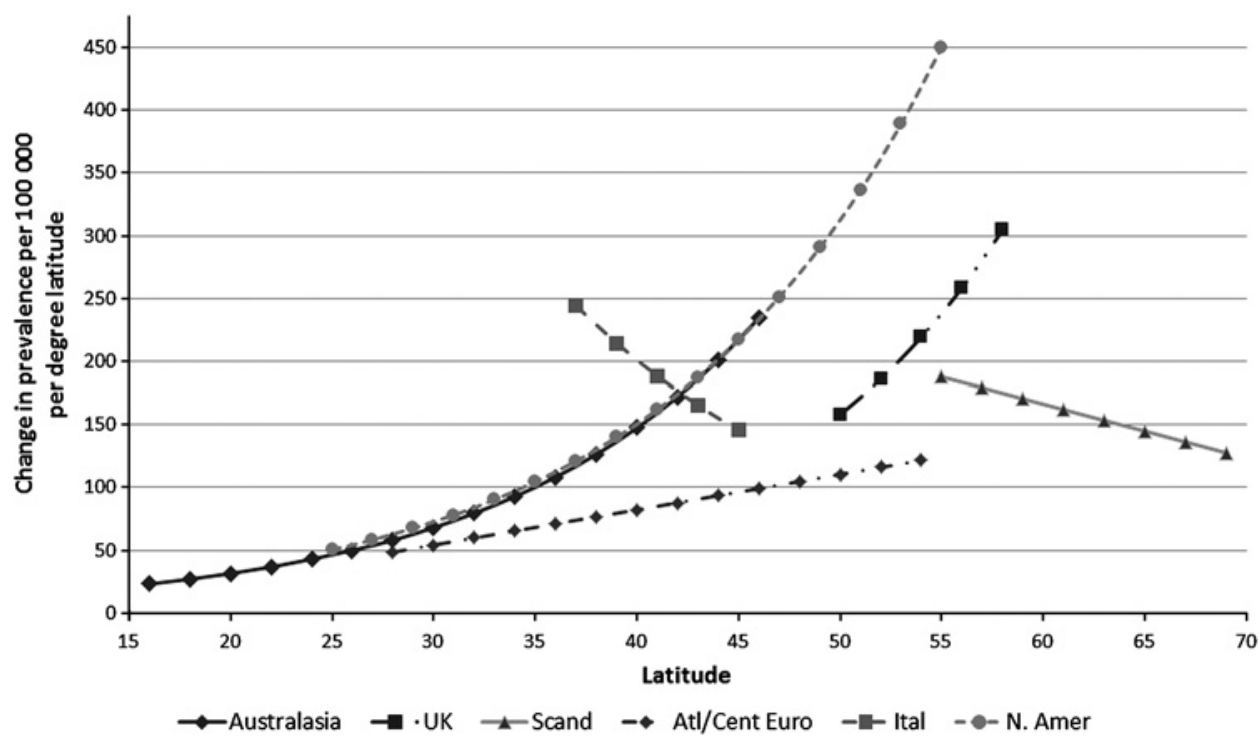


Table 5 Associations between latitude and time-adjusted agestandardised prevalence for the Italian, Western Europe and Europe regions, and with adjustment for HLA-DRB1 frequencies

\begin{tabular}{|c|c|c|}
\hline Region & $\begin{array}{l}\text { No of age-standardised } \\
\text { prevalence estimates }\end{array}$ & Slope $95 \% \mathrm{Cl}^{*}$ \\
\hline \multicolumn{3}{|l|}{ Italian region } \\
\hline $\begin{array}{l}\text { All prevalence } \\
\text { estimates }\end{array}$ & 31 & $-11.59(-20.17$ to -3.02$) \dagger$ \\
\hline $\begin{array}{l}\text { Adjusted for } \\
\text { HLA-DRB1§ }\end{array}$ & 31 & $5.99(-22.94$ to 34.91$)$ \\
\hline \multicolumn{3}{|l|}{ Western Europe } \\
\hline $\begin{array}{l}\text { All prevalence } \\
\text { estimates }\end{array}$ & 114 & $9.27(4.23$ to 14.33$) \neq$ \\
\hline $\begin{array}{l}\text { Only those with } \\
\text { HLA-DRB1 data }\end{array}$ & 99 & $7.70(3.19$ to 12.22$) \neq$ \\
\hline $\begin{array}{l}\text { Adjusted for } \\
\text { HLA-DRB1§ }\end{array}$ & 99 & $7.97(3.11$ to 12.84$) \neq$ \\
\hline \multicolumn{3}{|l|}{ Europe } \\
\hline $\begin{array}{l}\text { All prevalence } \\
\text { estimates }\end{array}$ & 162 & $5.57(2.34$ to 8.80$) \neq$ \\
\hline $\begin{array}{l}\text { Only those with } \\
\text { HLA-DRB1 data }\end{array}$ & 146 & $5.03(1.61$ to 8.46$) \neq$ \\
\hline $\begin{array}{l}\text { Adjusted for } \\
\text { HLA-DRB1§ }\end{array}$ & 146 & $6.71(2.43$ to 10.98$) \neq$ \\
\hline
\end{tabular}

${ }^{*}$ Slope $(95 \% \mathrm{Cl})=$ change in prevalence $/ 100000$ per degree of latitude $(95 \% \mathrm{Cl})$

†Statistically significant $(p<0.05)$.

$¥$ Statistically significant $(p<0.001)$.

$\S$ Adjustment for HLA-DRB1 allele frequencies includes adjustment for HLA-DRB1 *01, *03, $* 11, * 14$ and $* 15$.

published in languages other than English, allowing a more powerful evaluation of geographic and temporal changes in prevalence.

Our study improves upon the work of Zivadinov ${ }^{4}$ in our use of study weighting by the inverse of study variance. As in figure 1 of our paper, there are a number of small outliers, particularly in the crude analysis. If these studies are not weighted in proportion to their small size and high variance, they can potentially affect the interpretation of the associations measured. The study by Koch-Henriksen and Sørensen ${ }^{6}$ restricted their inclusion of studies, requiring a minimum of 20 cases. While this is one method of addressing variable study quality, this has the effect of moderating any potential gradient, since the number of cases, presuming a constant population, would decrease with decreasing latitude; removing studies with smaller prevalent cohorts would remove a greater proportion of studies at the lower extreme of latitude, biasing the results. Rather as we have done, the use of study weighting by the inverse of study variance would address any potential differences in study quality which might covary with case number, while preserving the maximal study inclusiveness.

A key feature of our study relative to most others ${ }^{1-3} 6$ is the use of age standardisation. As noted by Zivadinov, ${ }^{4}$ age standardisation is requisite for studies comparing aggregate-level data from different study regions, which can have significantly different age structures. While some have suggested that age standardisation was unnecessary, ${ }^{6}$ it made an important difference to the findings of Zivadinov, ${ }^{4}$ Alonso and Hernán, ${ }^{5}$ and our own.

Our analyses were strengthened by adjustment for prevalence year, which was significantly associated with prevalence independently of other covariates. Importantly, we observed an association between log-transformed prevalence and latitude prior to time adjustment, which was enhanced on simple adjustment for prevalence year, indicating that our findings are not a statistical artefact of the time-adjustment process. Interestingly, Koch-Henriksen and Sørensen ${ }^{6}$ also find a significant association between prevalence and prevalence year; however, they do not adjust their analyses of prevalence and latitude for it-doing so in our analysis significantly enhanced the magnitude and significance of the association between latitude and prevalence. Our results show that failure to adjust for prevalence year would underestimate the magnitude and significance of the latitudinal gradient (table 2), particularly when the meta-analysis includes studies over a wide range of time, as was the case here.

A novel feature of our analysis is the segmented, rather than simple, linear models used to evaluate the global gradient: the prevalence gradient increased with latitude, reaching a peak around $55^{\circ}$, before becoming a significant inverse gradient above $60^{\circ}$ (figure 1, table 3). This reduction in the gradient at higher latitudes was also observed by Zivadinov et $a l^{4}$; their use of a linear trend to evaluate the significance of the global gradient may contribute to their conclusion of an attenuation after age standardisation, rather than an enhancement as observed here.

For our HLA-DRB1 analyses, we were able to ascribe HLADRB1 allele frequencies with a much greater precision than attempted previously. Whereas previous studies ${ }^{36}$ have evaluated the relationship between prevalence, latitude and HLA-DRB1 at the national or supra-local level, we were able to assign HLADRB1 allele frequencies to the majority of the individual prevalence estimates in Europe using HLA-DRB1 surveys within geographically relevant areas. In an area of such genetic complexity as Europe, this is critical in evaluating the role of HLA-DRB1 in the latitudinal gradient.

\section{Study weakness}

Several weaknesses of this study need to be borne in mind. First, the analyses are based on prevalence estimates made in different study centres with varying degrees of case ascertainment and different study procedures. Our inclusion criteria excluded case series and other non-population-based estimates of prevalence. However, we did not attempt to grade and select studies for inclusion based on perceived study quality, because to do so requires objective information that is rarely fully reported in MS prevalence studies. Instead, we attempted to take some of the known factors into account in analyses, but we accept that it is not possible to do so completely.

We were not able to remove all residual between-study variance using information available to use on prespecified covariates. This residual variance was most pronounced at the global level; however, in regional analyses (data not shown) the covariates were successful in explaining a much larger part of the between-study variance. This added to confidence that the association of MS prevalence with model covariates-including latitude-is truly reflective of causal factors that correlate with latitude, most particularly environmental factors such as UV/ vitamin $\mathrm{D}$.

There are potential sources of bias in our own study procedures, including selection bias from inclusion of serially measured prevalence estimates at the same location or exclusion of non-peer-reviewed studies, and measurement bias from including studies making use of non-systematic diagnostic criteria. However, none of these factors had a material impact on our findings.

A further issue is that of publication bias. We have attempted to address publication bias by drawing our studies from a broad a range of sources, and including studies published in languages other than English, as well as including non-peer-reviewed studies in a subanalysis. Publication bias on the part of the individual study authors is less of a concern than in some other 
study types, because prevalence studies are necessarily less prone to publication bias by virtue of the absence of a 'null finding.' Furthermore, if authors do not pursue publication of findings that are not in marked contrast with previously reported estimates for their area, the published estimates nevertheless capture the regional variance, and the non-published findings would not materially change our conclusions.

\section{CONCLUSION}

We present here the largest and most comprehensive study of MS prevalence yet carried out, finding a significant positive association between latitude and prevalence at the global level, as well as in most regions of European descent. Our findings are inconsistent with preceding reviews of MS prevalence ${ }^{634}$ but in harmony with a methodologically similar meta-analysis of MS incidence. ${ }^{5}$ Our findings do not concur with all of the conclusions of previous meta analyses ${ }^{4}{ }^{6}$; however, we feel that the differences are accounted for by the improved methodologies as described. We feel that the inclusiveness and methodological improvements, particularly age standardisation and time adjustment, indicate that these findings are more representative of the current geoepidemiology of MS than previous studies. European exceptions to the gradient in the Scandinavia and North Atlantic, and Italian regions are explicable by behaviouralcultural and genetic factors that vary geographically within these regions.

In contradiction with work elsewhere, ${ }^{36}$ HLA-DRB1 variation did not account for the majority of the gradient in Europe, suggesting a greater role for environmental factors that vary by latitude, with the most prominent candidates being UV and vitamin $\mathrm{D}$. No doubt, genetic and environmental factors interact to manifest in the variation in MS prevalence observed, but there are insufficient data available on the distribution of HLADRB1 alleles to quantify the proportions precisely. The information gleaned from this demonstration of the existence of a latitudinal gradient for MS prevalence will further the understanding of factors leading to MS and, potentially, help lead to its resolution.

Acknowledgements We thank the various authors whose published works were requisite for this study, and we would especially like to thank the following authors for their personal correspondences: F Al-Himyari at the Babylon University in Babylon City, Iraq; S Beer at the Klinik Valens Rehabilitation Centre in Valens, Switzerland; $\mathrm{J}$ Bentzen at the University of Southern Denmark in Copenhagen, Denmark; A Bhigjee at Inkosi Albert Luthuli Central Hospital in Durban, South Africa; E Celius at Oslo University Hospital in Ullevål, Norway; DAS Compston at the University of Cambridge in Cambridge, UK; N Gryten-Torkildsen at Haukeland University Hospital in Bergen, Norway; H Houzen at Obihiro Kosei General Hospital in Hokkaido, Japan; W Ingram at Peninsula Medical School in Plymouth, UK; J Kurtzke at Georgetown University in Washington, DC, USA; C-H Lai at Changhua Christian Hospital in Changhua, Taiwan; J Larsen at the University of Bergen in Bergen, Norway; R Lonergan at St Vincent's Private Hospital in Dublin, Ireland; E Materljan at the University of Rijeka in Rijeka, Croatia; K-M Myhr at the University of Bergen in Bergen, Norway; A Nicoletti at the University of Catania in Catania, Italy; M Nino at Hokkaido University in Sapporo, Japan; N Robertson at Cardiff University in Cardiff, UK; C Sagnes-Raffy at the Centre Hospitalier, University of Toulouse in Toulouse, France; J Sepčić at the University of Rijeka in Rijeka, Croatia; C Smestad at Oslo University Hospital, Ullevål, Norway; HF Tseng at Kaiser Permanente, Southern California in Pasadena, California, USA; N Tubridy at St Vincent's Private Hospital in Dublin, Ireland; D Williamson at the Division of Reproductive Health of the Centers for Disease Control and Prevention in Atlanta, Georgia, USA; and J Zajicek at the Peninsula Medical School in Plymouth, UK

Funding SSJ is supported by a Menzies Postgraduate Research Scholarship. IVdM is supported by an NHMRC Training Fellowship.

\section{Competing interests None.}

Contributors The project was conceived and planned by SSJ. The data collection/ literature review was done by SSJ. SSJ, LB, PO and BT were involved in the conception of analyses used. SSJ implemented statistical analyses, supervised by LB, and PO undertook segmented analyses. SSJ, BT, LB and IVdM were involved in the initial drafting of manuscript. SSJ had full access to all of the aggregate-level data included in this study and takes responsibility for the integrity and accuracy of the data analyses therein.

Provenance and peer review Not commissioned; externally peer reviewed.

\section{REFERENCES}

1. Kurtzke JF. General features on the prevalence of multiple sclerosis. J Indian Med Prof 1964:11:4896-901.

2. Kurtzke JF. A reassessment of the distribution of multiple sclerosis. Acta Neurol Scand 1975:51:137-57.

3. Rosati G. The prevalence of multiple sclerosis in the world: an update. Neurol Sci 2001;22:117-39.

4. Zivadinov R, Iona L, Monti-Bragadin L, et al. The use of standardized incidence and prevalence rates in epidemiological studies on multiple sclerosis. A meta-analysis study. Neuroepidemiology 2003;22:65-74.

5. Alonso A, Hernan MA. Temporal trends in the incidence of multiple sclerosis: a systematic review. Neurology 2008;71:129-35.

6. Koch-Henriksen N, Sørensen PS. The changing demographic pattern of multiple sclerosis epidemiology. Lancet Neurol 2010;9:520-32.

7. Hammond SR, McLeod JG, Millingen KS, et al. The epidemiology of multiple sclerosis in three Australian cities: Perth, Newcastle and Hobart. Brain 1988;111:1-25.

8. Taylor B, Pearson JF, Clarke G, et al. MS prevalence in New Zealand, an ethnically and latitudinally diverse country. Mult Scler 2010;16:1422-31.

9. Kuroiwa Y, Shibasaki H, Ikeda M. Prevalence of multiple sclerosis and its north-tosouth gradient in Japan. Neuroepidemiology 1983;2:62-9.

10. Vukusic S, Van Bockstael V, Gosselin S, et al. Regional variations in the prevalence of multiple sclerosis in French farmers. J Neurol Neurosurg Psychiatry 2007:78:707-9.

11. Kurtzke JF, Beebe GW, Norman JE Jr. Epidemiology of multiple sclerosis in US veterans: 1. Race, sex, and geographic distribution. Neurology 1979;29:1228-35.

12. Melcon MO, Gold L, Carra A, et al. Argentine Patagonia: prevalence and clinical features of multiple sclerosis. Mult Scler 2008;14:656-62.

13. Poppe AY, Wolfson C, Zhu B. Prevalence of multiple sclerosis in Canada: a systematic review. Can J Neurol Sci 2008:35:593-601.

14. Grønlie SA, Myrvoll E, Hansen G, et al. Multiple sclerosis in North Norway, and firs appearance in an indigenous population. J Neurol 2000;247:129-33.

15. Rosati G. Descriptive epidemiology of multiple sclerosis in Europe in the 1980s: a critical overview. Ann Neurol 1994;36(Suppl 2):S164-74.

16. van der Mei IA, Ponsonby $A L$, Dwyer $T$, et al. Past exposure to sun, skin phenotype, and risk of multiple sclerosis: case-control study. BMJ 2003;327:316.

17. Tremlett H, van der Mei IA, Pittas F, et al. Monthly ambient sunlight, infections and relapse rates in multiple sclerosis. Neuroepidemiology 2008;31:271-9.

18. Simpson S Jr, Taylor B, Blizzard L, et al. Higher 25-hydroxyvitamin D is associated with lower relapse risk in MS. Ann Neurol 2010;68:193-203.

19. Middleton D, Menchaca L, Rood H, et al. Tissue antigens 2003;61:403-07. New Allele Frequency Database. http://www.allelefrequencies.net.

20. Breslow NE, Day NE. Statistical Methods in Cancer Research: Volume II-The Design and Analysis of Cohort Studies. Lyon: International Agency for Research on Cancer, 1987.

21. Population-Division: United States Census Bureau, 2010. International Data Base. http://www.census.gov/ipc/www/idb/index.php.

22. Kleinbaum DG, Kupper LL, Muller KE, et al. Multiple regression analysis: general considerations. In: Kugushev A, ed. Applied Regression Analysis and Multivariable Methods. 3rd edn. South Melbourne: Brooks/Cole Publishing Company, 1998:111-35.

23. Schmidt H, Williamson D, Ashley-Koch A. HLA-DR15 haplotype and multiple sclerosis: a HuGE review. Am J Epidemiol 2007;165:1097-109.

24. Einarsdottir E, Egerbladh I, Beckman L, et al. The genetic population structure of northern Sweden and its implications for mapping genetic diseases. Hereditas 2007; 144:171-80.

25. de Graaf AS. Multiple sclerosis in northern Norway. Eur Neurol 1974:11:281-95.

26. Grønning M, Mellgren SI. Multiple sclerosis in the two northernmost counties of Norway. Acta Neurol Scand 1985;72:321-7.

27. Kampman MT, Brustad M. Vitamin D. A candidate for the environmental effect in multiple sclerosis—observations from Norway. Neuroepidemiology 2008;30:140-6.

28. Freisling H, Fahey MT, Moskal A, et al. Region-specific nutrient intake patterns exhibit a geographical gradient within and between European countries. J Nutr 2010;140:1280-6.

29. Brustad M, Alsaker E, Engelsen 0 , et al. Vitamin D status of middle-aged women at 65-71 degrees $\mathrm{N}$ in relation to dietary intake and exposure to ultraviolet radiation. Public Health Nutr 2004; 7:327-35.

30. Burgaz A, Akesson A, Oster A, et al. Associations of diet, supplement use, and ultraviolet B radiation exposure with vitamin D status in Swedish women during winter. Am J Clin Nutr 2007;86:1399-404.

31. Brustad M, Sandanger T, Aksnes L, et al. Vitamin D status in a rural population of northern Norway with high fish liver consumption. Public Health Nutr 2004;7:783-9.

32. Elmadfa I, Weichselbaum E. Energy and Nutrient Intake in the European Union. European Nutrition And Health Report 2004 (Forum of Nutrition/Bibliotheca Nutritio Et Dieta). Vienna: Karger, 2005 
33. Brustad M, Edvardsen K, Wilsgaard T, et al. Seasonality of UV-radiation and vitamin D status at 69 degrees north. Photochemical Photobiol Sci 2007;6:903-8. Official journal of the European Photochemistry Association and the European Society for Photobiology.

34. Munger KL, Levin LI, Hollis BW, et al. Serum 25-hydroxyvitamin D levels and risk of multiple sclerosis. JAMA 2006:296:2832-8.
35. Munger KL, Zhang SM, O'Reilly E, et al. Vitamin D intake and incidence of multiple sclerosis. Neurology 2004;63:939.

36. Handel AE, Handunnetthi L, Giovannoni G, et al. Genetic and environmental factors and the distribution of multiple sclerosis in Europe. Eur J Neurol 2010:17:1210-14.

37. Orton SM, Herrera BM, Yee IM, et al. Sex ratio of multiple sclerosis in Canada: a longitudinal study. Lancet Neurol 2006:5:932-6.

\section{Have confidence in your decision making.}
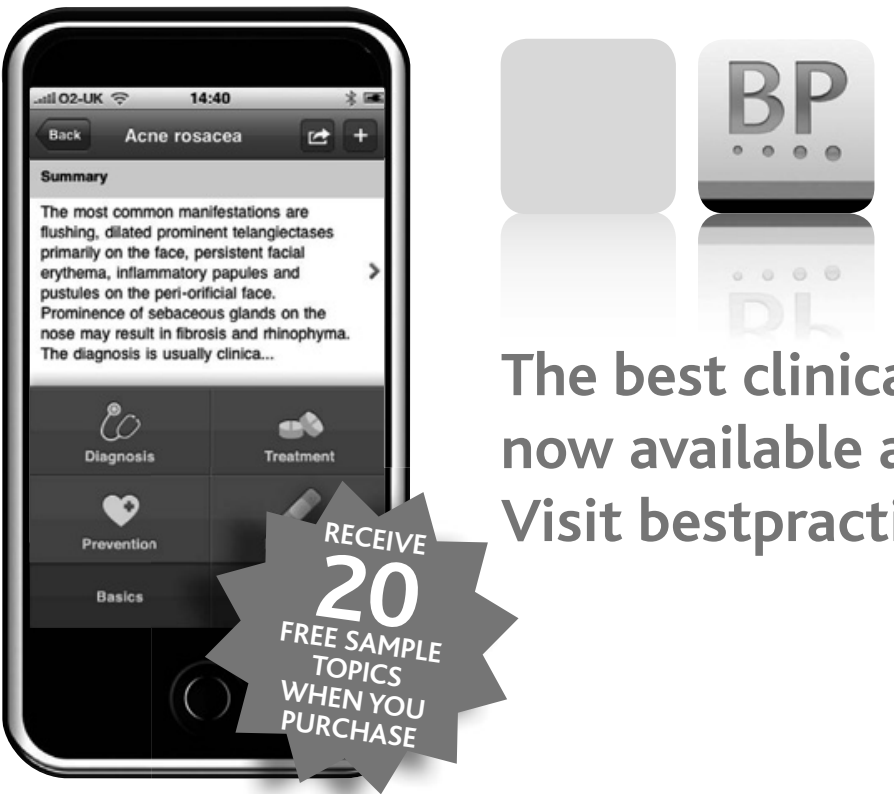

The best clinical decision support tool is now available as an app for your iPhone. Visit bestpractice.bmj.com/app

\section{clinicians $\bullet$ medical students $\bullet$ nurses $\bullet$ healthcare practitioners}

